\title{
Hipocalcemia Crónica por Anticorpos Anti-Recetor do Cálcio
}

\author{
Chronic Hypocalcemia due to Anti-Calcium Sensing Receptor Antibodies
}

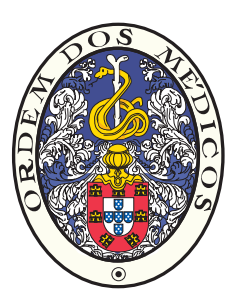

\author{
Pedro MARQUES ${ }^{1}$, Rita SANTOS ${ }^{1}$, Branca CAVACO ${ }^{2}$, Valeriano LEITE ${ }^{1,2,3}$ \\ Acta Med Port 2014 May-Jun;27(3):399-402
}

\section{RESUMO}

Introdução: O hipoparatiroidismo cursa com hipocalcemia e é mais frequentemente registado após cirurgia cervical. A etiologia autoimune é mais rara e difícil de diagnosticar.

Caso clínico: Mulher, 52 anos, sem antecedentes pessoais, medicamentosos ou familiares relevantes, referenciada por hipocalcemia e calcificação dos núcleos da base, detetados no decurso de investigação de quadro de mialgias. Além de hipocalcemia (4,6 mg/dL), foi verificada hiperfosfatemia $(8,7 \mathrm{mg} / \mathrm{dL})$, hormona paratiroideia indetetável, calciúria, fosfatúria e magnesúria baixas. A análise molecular do gene CaSR excluiu mutações germinais. A pesquisa de anticorpos anti-receptor sensível do cálcio (anti-CaSR) foi positiva. Atualmente está assintomática e normocalcémica sob terapêutica com cálcio e vitamina $D$.

Discussão: Embora rara, a hipocalcemia por hipoparatiroidismo autoimune deve ponderar-se em adultos sem antecedentes de cirurgia cervical, medicação hipocalcemiante, história familiar ou fenótipo sugestivo de doença genética. Hormona paratiroideia diminuída ou indetetável exclui pseudohipoparatiroidismo e a positividade para anti-CaSR confirma o diagnóstico.

Palavras-chave: Hipocalcemia; Hipoparatiroidismo; Receptores de Detecção de Cálcio.

\section{ABSTRACT}

Introduction: Hypoparathyroidism is an entity associated with hypocalcemia, more frequently a consequence of neck surgery. An autoimmune etiology is rare and its diagnosis difficult to establish.

Clinical report: 52 year-old woman, with irrelevant past medical history and no significant familial conditions, referred because of hypocalcemia and basal ganglia calcifications, detected in the course of investigation of myalgias. Besides hypocalcemia (4.6 mg/ $\mathrm{dL}$ ), hyperphosphatemia $(8.7 \mathrm{mg} / \mathrm{dL})$, undetectable parathyroid hormone and low urinary calcium, phosphorus and magnesium were present. Molecular analysis of CaSR gene excluded germinal mutations. Anti-calcium sensing receptor antibodies (anti-CaSR) were present. The patient is asymptomatic and normocalcemic under treatment with calcium and vitamin D.

Discussion: Although rare, hypocalcemia due to anti-CaSR hypoparathyroidism must be considered in the absence of previous neck surgery, hypocalcemic drugs, familial history or phenotype suggesting a genetic disorder. Low or undetectable parathyroid hormone excludes pseudohypoparathyroidism and anti-CaSR positivity establishes the diagnosis.

Keywords: Hypocalcemia; Hypoparathyroidism; Autoantibodies; Receptors, Calcium-Sensing.

\section{INTRODUÇÃO}

A hipocalcemia é definida como baixo nível sérico de cálcio ionizado ou de cálcio total corrigido à albumina. ${ }^{1} \mathrm{~A}$ calcemia é mantida em níveis fisiológicos sobretudo pela ação da hormona paratiroideia (PTH) e vitamina $D$ activa $\left(1,25(\mathrm{OH})_{2} \mathrm{D}\right)$. Várias situações cursam com hipocalcemia sendo o hipoparatiroidismo (HipoPT) a mais frequente. ${ }^{2} \mathrm{~A}$ secreção baixa ou inexistente de $\mathrm{PTH}$ é inadequada para mobilizar cálcio ósseo, reabsorver cálcio a nível renal e estimular a 1 $\alpha$-hidroxílase renal, resultando em níveis baixos de $1,25(\mathrm{OH})_{2} \mathrm{D}$ e deficiente absorção gastrointestinal de cálcio. ${ }^{1,3} \mathrm{O}$ HipoPT pode ser congénito ou adquirido sendo a causa mais frequente a cirurgia cervical. ${ }^{1}$ (Tabela 1)
A autoimunidade é uma causa de HipoPT que pode aparecer isoladamente ou como componente de síndromes poliglandulares autoimunes, nomeadamente do tipo $1 . .^{4-6} \mathrm{~A}$ primeira evidência de HipoPT autoimune foi apontada por Blizzard em 1966, que identificou anticorpos anti-paratiróide. ${ }^{7}$ Em 1993 clonou-se pela primeira vez o recetor sensível do cálcio (CaSR) ${ }^{8}$ e em 2003/ 2004 documentaram-se anticorpos estimuladores e inibidores do recetor sensível do cálcio (anti-CaSR). ${ }^{9,10}$ Os anti-CaSR estimuladores vão ativar o recetor condicionando uma diminuição da secreção de PTH. ${ }^{4}$

O CaSR é um recetor membranar acoplado à proteína $\mathrm{G}$

1. Serviço de Endocrinologia. Instituto Português de Oncologia de Lisboa Francisco Gentil. Lisboa. Portugal.

2. Unidade de Investigação em Patobiologia Molecular. Instituto Português de Oncologia de Lisboa Francisco Gentil. Lisboa. Portugal.

3. Centro de Estudos de Doenças Crónicas. Faculdade de Ciências Médicas. Universidade Nova de Lisboa. Lisboa. Portugal.

Recebido: 13 de Julho de 2013 - Aceite: 23 de Dezembro de 2013 | Copyright @ Ordem dos Médicos 2014 
Tabela 1 - Causas e diagnóstico diferencial de hipoparatiroidismo

\section{Causa/Mecanismo do Hipoparatiroidismo Observações}

Destruição/exérese das paratiróides com insuficiente/ausência de secreção de PTH

* Pós-cirurgia

${ }^{*}$ Autoimune
Causa mais frequente de HipoPT; pode ser transitório ou definitivo (persiste mais de 6 meses após cirurgia)

HipoPT isolado/associado a endocrinopatias múltiplas

Dois mecanismos patogénicos são admitidos:

1) Destruição autoimune mediada por células $T$ contra a proteína paratiroideiaespecífica nacht-leucine-rich protein 5 (NALP5)

2) Modulação autoimune da atividade do CaSR mediada por anti-CaSR

$\begin{array}{ll}\text { * Destruição por irradiação } & \text { Raro } \\ \text { * Infiltração metastática } & \text { Rara }\end{array}$

* Deposição de metais pesados Mais frequente nas talassemias ( $>10 \%)$; menos frequente na hemocromatose, e muito raro na doença de Wilson

\section{Défice reversível na secreção ou ação da PTH}

${ }^{*}$ Hipomagnesemia

Associada a condições como o alcoolismo, mal-nutrição ou má-absorção, diarreia, diabetes, fármacos (diuréticos, cisplatina, aminoglicosídeos), perda de magnésio por lesão renal (pielonefrite crónica; nefropatias; acidose tubular renal)

* Hipermagnesemia

Pode ocorrer no seguimento de terapêuticas tocolíticas ou em doentes sob suplementos de magnésio, anti-ácidos ou laxantes

*Ativação constitutiva do CaSR

Por mutação do gene ou mais raramente por anticorpos estimuladores do CaSR.

Doenças genéticas que afetam a biossíntese da PTH ou génese das paratiróides

* Mutações no gene da PTH

* Mutações ou deleções de fatores de transcrição e outros envolvidos no desenvolvimento das paratiróides

* Mutações no ADN mitocondrial

Resistência à ação da PTH

${ }^{*}$ Pseudo-HipoPT tipo 1a
Responsável por HipoPT isolado

Podem apresentar-se isoladamente ou como parte de síndromes genéticos mais complexos

Pode associar-se a outros distúrbios metabólicos ou a anomalias congénitas

Características fenotípicas típicas (fácies redonda, estatura baixa, obesidade, braquidactilia, atraso mental, ossificação ectópica). Bioquimicamente há hipocalcemia e PTH elevada. Pode associar-se a outras endocrinopatias, como hipotiroidismo (resistência à TSH) e menos frequentemente hipogonadismo (resistência às gonadotrofinas). A maioria decorre de mutações inativadoras no gene GNAS.

${ }^{*}$ Pseudo-HipoPT tipo 1b

Sem características fenotípicas. Resistência seletiva para a PTH causada por defeitos no gene GNAS.

Mais raro. A causa não está bem definida. Ocorrência hereditária ou esporádica.

* Pseudo-HipoPT tipo 2 dicada apenas com ibuprofeno por mialgias. Assintomática até aos 42 anos (ano 2000), altura em que inicia quadro de mialgias, espasmos musculares e parestesias. Terá realizado vários exames complementares de diagnóstico aos quais não tivemos acesso, e terapêuticas que não sabe especificar.

Foi referenciada em 2010 por hipocalcemia, hiperfosfatemia e calcificação bilateral dos núcleos da base em TC crânio-encefálica (Fig. 1). Ao exame físico destacavam-se sinais de Chvostek e Trousseau positivos. A avaliação 

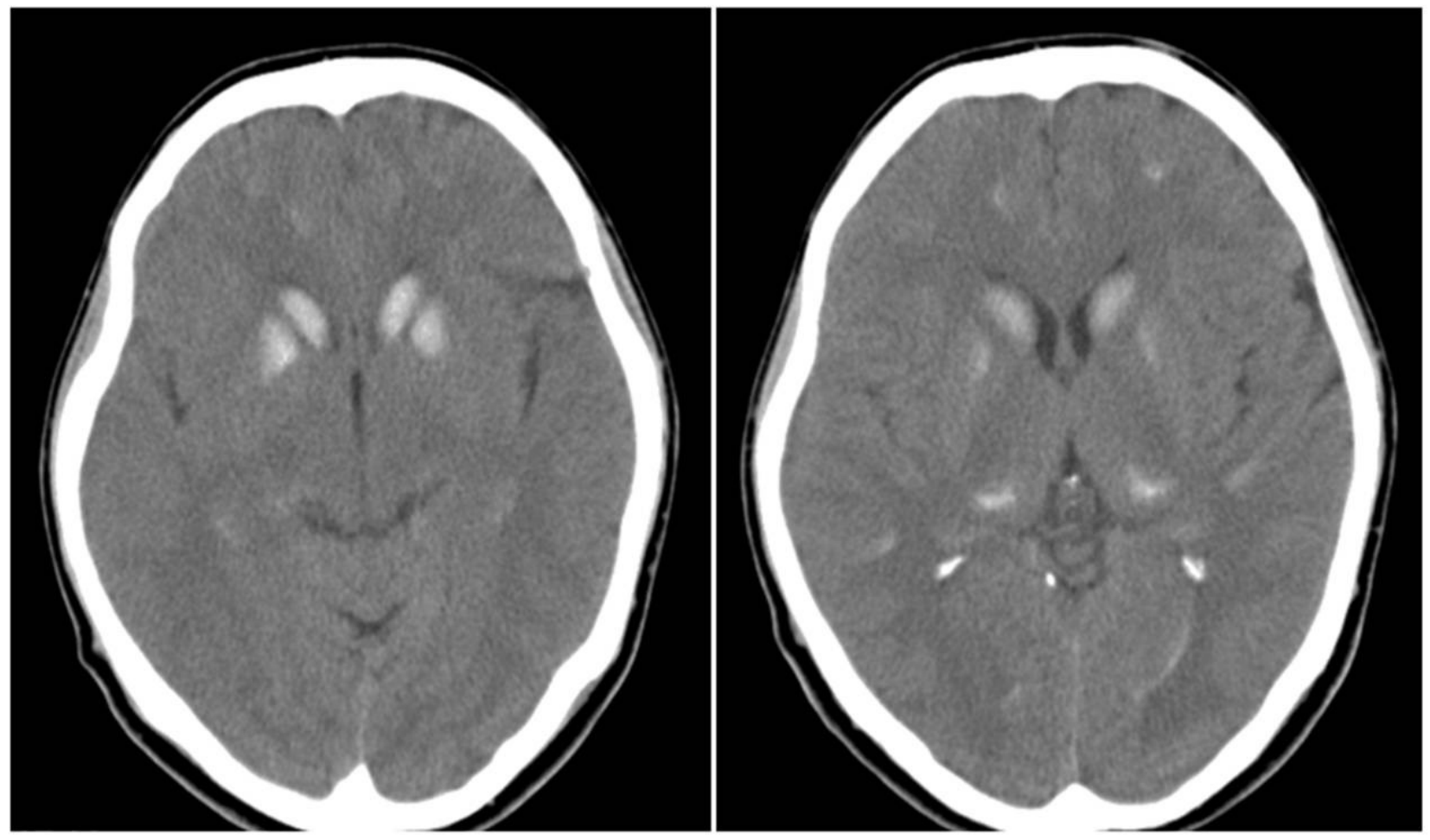

Figura 1 - TC crânio-encefálica (2010) revelando calcificação bilateral dos núcleos da base

analítica revelou uma hipocalcemia de $4,6 \mathrm{mg} / \mathrm{dL}$ [8,4-10,2] e hiperfosfatemia de $8,7 \mathrm{mg} / \mathrm{dL}$ [2,3-4,7], com hipocalciúria $(39,5 \mathrm{mg} / 24 \mathrm{~h}[100-300])$, hipofosfatúria $(304,1 \mathrm{mg} / 24 \mathrm{~h}$ [400-1300]) e hipomagnesúria $(40,7$ mg/ 24h [72,9-121,5]); hemograma, glicemia, função renal e hepática, sódio, potássio e magnésio sem alterações. Dos doseamentos hormonais destacava-se PTH indoseável $(<3,0 \mathrm{mg} / \mathrm{mL}$ ) e anticorpos anti-peroxidase tiroideia positivos, sendo os doseamentos de 25(OH)D (33,4 ng/ mL [9-45]), 1,25(OH) $\mathrm{D}$ (47,5 pg/ mL [20-50]), TSH,T4 livre, prolactina, LH e FSH dentro de valores de referência. A ecografia renal excluiu litíase. A análise molecular do gene CaSR excluiu a presença de mutações germinais e a pesquisa de anti-CaSR foi positiva.

Iniciou-se terapêutica diária com 4500 mg de carbonato de cálcio (equivalente a $1800 \mathrm{mg}$ de cálcio) e $0,5 \mathrm{mcg}$ de calcitriol, com franca melhoria clínica e normalização da calcemia. A doente está atualmente assintomática e normocalcémica sob $3000 \mathrm{mg}$ de carbonato de cálcio e 0,5 mcg de calcitriol diários.

De referir que aos 53 anos (2011) foi operada a cataratas bilaterais.

\section{DISCUSSÃO}

A sintomatologia neuromuscular, neuropsiquiátrica ou cardiovascular de hipocalcemia surge habitualmente para valores $<7-7,5 \mathrm{mg} / \mathrm{dL}$ e a sua gravidade correlaciona-se com a magnitude e velocidade de declínio do cálcio, estado ácido-base, presença de hipomagnesemia e/ou hiperatividade simpática. ${ }^{1,2}$ Calcemias na ordem dos 4,6 mg/ $\mathrm{dL}$, instaladas subitamente têm expressão clínica exube- rante, mas em contexto crónico podem ser assintomáticas ou apresentar manifestações discretas, como era o caso da doente.

As calcificações dos núcleos da base ${ }^{11}$ e as cataratas sub-capsulares $^{12}$ associam-se ao HipoPT e estão ambas presentes na doente. A calcificação dos núcleos da base ocorre em $73,8 \%$ dos doentes com HipoPT estando relacionada com o ratio cálcio/fósforo e a duração da hipocalcemia. ${ }^{11} \mathrm{O}$ mecanismo de desenvolvimento de cataratas na hipocalcemia não está totalmente esclarecido; Hough sugere que a ativação do CaSR pode favorecer a sua formação. ${ }^{12}$

HipoPT e PseudohipoPT foram considerados no início como possíveis causas da hipocalcemia. A ausência de outras manifestações tornou as doenças infiltrativas pouco prováveis. Excluiu-se hipo ou hipermagnesemia como causa de HipoPT funcional. A ausência de fenótipo sugestivo ou história familiar e instalação do quadro em idade adulta afastou outras causas, nomeadamente as congénitas.

A presença de PTH indetetável excluiu PseudohipoPT e assumiram-se como diagnósticos mais prováveis: HipoPT autoimune ou HipoPT autossómico dominante. ${ }^{8}$ Nesta doente a positividade dos anticorpos anti-peroxidase tiroideia indiciava predisposição autoimune, apesar da inexistência de disfunção tiroideia. ${ }^{5}$ Procedeu-se à análise molecular do gene CaSR que excluiu a presença de mutações germinais afastando a hipótese de hipocalcemia autossómica dominante. Foram pesquisados os anticorpos anti-CaSR que foram positivos. Os estudos funcionais dos anti-CaSR não foram realizados, mas no contexto parecem apresentar atividade estimuladora. Assim, estabeleceu-se 
o diagnóstico final de HipoPT autoimune por anticorpos anti-CaSR provavelmente estimuladores.

Do ponto de vista clinico e laboratorial, o HipoPT por anti-CaSR e a hipocalcemia autossómica dominante sobrepõem-se dado que a sua fisiopatologia envolve a activação do CaSR. Ambos cursam com hipocalcemia, hiperfosfatemia e PTH indoseável, e condicionam um quadro clínico característico de HipoPT. ${ }^{1,2}$ No entanto, o HipoPT por anti-CaSR pode ser apresentar flutuações na sua expressão e evolução clínica, provavelmente devido à variação do título de anticorpos ao longo do tempo..$^{8,9,13}$ No HipoPT por anti-CaSR parece haver apenas um defeito funcional, e não uma lesão irreversível das glândulas paratiroideias, típica de outras formas de HipoPT autoimune. 4,9,14

No grupo dos HipoPT autoimunes, o HipoPT por anti-CaSR estimuladores destaca-se como raro e a sua prevalência ainda não está definida. ${ }^{6,9,15}$ Vários estudos têm avaliado a prevalência de anti-CaSR em HipoPT idiopáticos; Tomar et al refere ser de 12,9\% num trabalho recente. ${ }^{14,15}$

O tratamento do HipoPT envolve a utilização de calcitriol associado ao cálcio. Estudos recentes têm avaliado o papel dos análogos de $\mathrm{PTH}$, uma terapêutica promissora em termos de eficácia (redução das necessidades de cálcio e calcitriol) e de segurança (prevenção de hipercalciúria,

\section{REFERÊNCIAS}

1. Shoback D. Hypoparathyroidism. N Engl J Med. 2008;359:391-403.

2. Al-Azem H, Khan A. Hypoparathyroidism. Best Pract Res Clin Endocrinol Metab. 2012;26:517-22.

3. Mitchell D, Regan S, Cooley M, Lauter K, Vrla M, Becker C, et al. Longterm follow-up of patients with hypoparathyroidism. J Clin Endocrin Metab. 2012;97:4507-14.

4. Brown E. Anti-parathyroid and anti-calcium sensing receptor antibodies in autoimmune hypoparathyroidism. Endocrinol Metab Clin North Am. 2009;38:437-46.

5. Fierabracci A, Bizzarri C, Palma A, Milillo A, Bellacchio E, Cappa M. A novel heterozygous mutation of the AIRE gene in a patient with autoimune polyendocrinopathy-candidiasis-ectodermal dystrophy syndrome (APECED). Gene. 2012;511:113-7.

6. Kemp E, Gavalas N, Akhtar S, Krohn K, Pallais J, Brown E, et al. Mapping of human autoantibody binding sites on the calcium-sensing receptor. J Bone Miner Res. 2010;25:132-40.

7. Blizzard R, Chee D, Davis $W$. The incidence of parathyroid and other antibodies in the sera of patients with idiopathic hypoparathyroidism. Clin Exp Immunol. 1966;1:119-28.

8. Brown E, Gamba G, Riccardi D, Lombardi M, Butters R, Kifor O, et al. Cloning and characterization of an extracellular $\mathrm{Ca}(2+)$-sensing receptor from bovine parathyroid. Nature. 1993;366:575-80.

9. Kifor O, McElduff A, Leboff M, Moore F, Butters R, Gao P, et al. Activating antibodies to the calcium-sensing receptor in two patients with autoim- lítiase renal e nefrocalcinose). ${ }^{1,14}$ Os objetivos são atingir o controlo sintomático e uma calcemia na ordem dos $8-8,5$ $\mathrm{mg} / \mathrm{dL}$, bem como uma calciúria $<300 \mathrm{mg} / 24$ horas. $^{1}$

O HipoPT por anti-CaSR deve ser ponderado em adultos, sem cirurgia cervical prévia, medicação hipocalcemiante ou fenótipo sugestivo de doença genética. PTH diminuída ou indoseável exclui pseudo-HipoPT e a presença de anti-CaSR estabelece o diagnóstico.

\section{AGRADECIMENTOS}

Os autores agradecem a Nicole Fabien, Diretora do Laboratório de Imunologia e da Unidade Funcional de Autoimunidade do Centre Hospitalier Lyon-Sud, Hospices Civils de Lyon, Pierre-Bénite, França, pela disponibilidade na determinação dos anticorpos anti-CaSR.

\section{CONFLITOS DE INTERESSE}

Os autores declaram a inexistência de conflitos de interesse.

\section{FONTES DE FINANCIAMENTO}

Os autores declaram a inexistência de fontes de financiamento.

mune hypoparathyroidism. J Clin Endocrinol Metab. 2004;89:548-56.

10. Kifor O, Moore F, Delaney M, Garber J, Butters R, Gao P, et al. A syndrome of hypocalciuric hypercalcemia caused by autoantibodies directed at the calcium-sensing receptor. J Clin Endocrinol Metab. 2003;88:60-72.

11. Goswani R, Sharma R, Sreenivast V, Gupta N, Ganapathy A, Das S Prevalence and progression of basal ganglia calcification and its pathogenic mechanism in patients with idiopathic hypoparathyroidism. Clin Endocrinol. 2012:77:200-6.

12. Hough T, Bogani D, Cheeseman M, Favor J, Nesbit M, Thakker R, et al. Activating calcium-sensing receptor mutation in the mouse is associated with cataracts and ectopic calcification. Proc Natl Acad Sci U S A. 2004;101:13566-71.

13. Posillico JT, Wortsman J, Srikanta S, Eisenbarth GS, Mallette LE, Brown EM. Parathyroid cell surface autoantibodies that inhibit parathyroid hormone secretion from dispersed human parathyroid cells. J Bone Miner Res. 1986;1:475-83.

14. Bilezikian JP, Khan A, Potts Jr JT, Brandi ML, Clarke BL, Shoback D, et al. Hypoparathyroidism in the adult: epidemiology, diagnosis, pathophysiology, target organ involvement, treatment, and challenges for future research. J Bone Miner Res. 2011;26:2317-37.

15. Tomar N, Gupta N, Goswami R. Calcium-sensing receptor autoantibodies and idiopathic hypoparathyroidism. J Clin Endocrinol Metab. 2013;98:3884-91 


\section{Hipocalcemia Crónica por Anticorpos Anti-Recetor do Cálcio \\ Acta Med Port 2014:27:399-402}

Publicado pela Acta Médica Portuguesa, a Revista Científica da Ordem dos Médicos

Av. Almirante Gago Coutinho, 151

1749-084 Lisboa, Portugal.

Tel: +351218428215

E-mail: submissao@actamedicaportuguesa.com

www.actamedicaportuguesa.com

ISSN:0870-399X | e-ISSN: 1646-0758

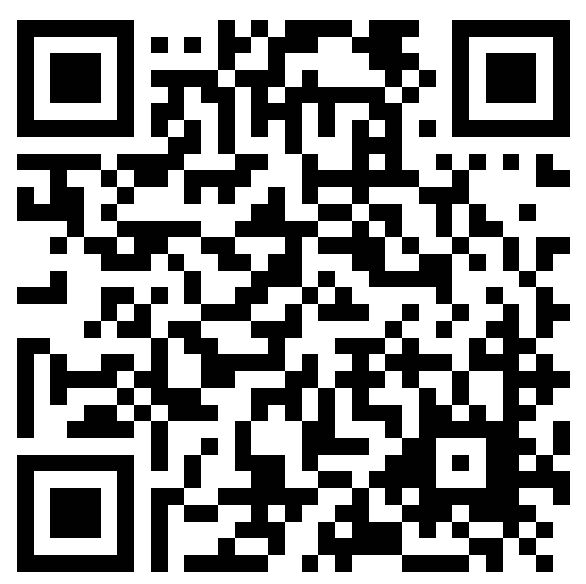

